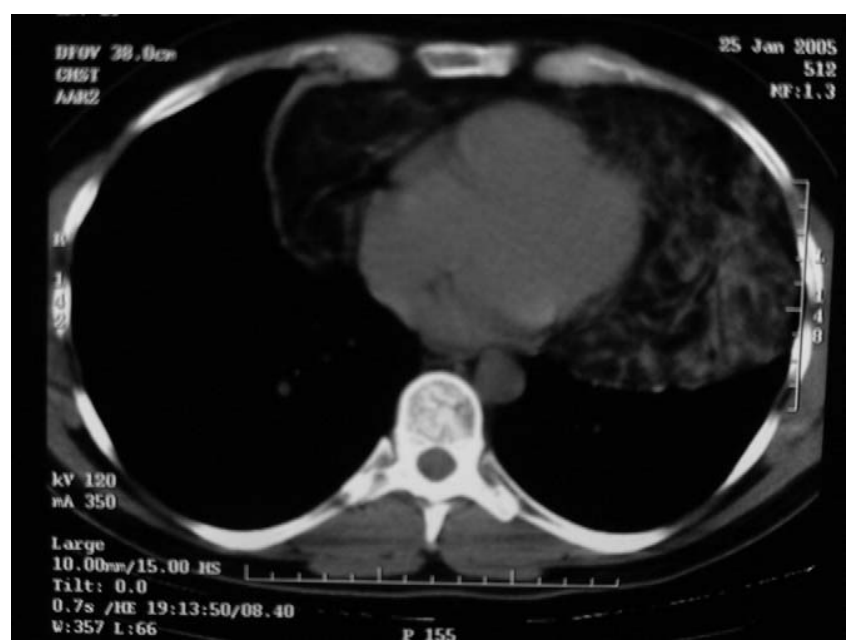

Figure 2. Spiral computed tomographic scan identified a massive heterogeneous mass with fat attenuation, with soft tissue extending widely into the bilateral inferior hemithoraces.
According to our review of the literature, there has been described only a single case of thymolipoma that seemed to produce CA $19-9,{ }^{5}$ a protein originally identified on the surface of colon cancer cells by using murine monoclonal antibodies. Interestingly, the thymolipoma in our case is associated with an increased acetylcholine antibody titer without clinical evidence of myasthenia gravis. Studies of larger case series are necessary to elucidate the relationships between a high production of CA 19-9 and an increased acetylcholine antibody titer in patients with thymolipoma.

\section{References}

1. Moran CA, Rosado-de-Christenson M, Suster S. Thymolipoma: clinicopathologic review of 33 cases. Mod Pathol. 1995;8:741-4.

2. van Hoeven KH, Brennan MF. Lipothymoadenoma of the parathyroid. Arch Pathol Lab Med. 1993;117:312-4.

3. Hall GFM. A case of thymolipoma with observations on a possible relationship to intrathoracic lipomata. Br J Surg. 1948;36:321-4.

4. Havlicek F, Rosai J. A sarcoma of thymic stroma with features of liposarcoma. Am J Clin Pathol. 1984;82:217-24.

5. Shinichi M, Kan O, Masafumi H, Masakatsu H, Takayuki S. Thymolipoma with high production of carbohydrate antigen 19-9. J Thorac Cardiovasc Surg. 2004;127:1845-7.

\title{
Single-stage repair of a large acquired tracheoesophageal fistula with interposition of 2 muscle pedicle flaps and laparoscopic gastrojejunostomy
}

Vishwanath Golash, MS, FRCS, Salalah, Sultanate of Oman

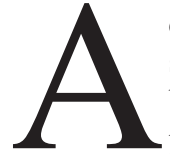

cquired tracheoesophageal fistula (TEF) is a rare but serious complication of prolonged endotracheal intubation. The main causative factor probably is the pressure of the overinflated cuff, leading to ischemia and tissue necrosis. The presence of a nasogastric tube adds further to the compression against the endotracheal cuff, resulting in TEF. I present the successful repair of a large TEF as a single-stage procedure.

From the Department of Surgery, Sultan Qaboos Hospital, Salalah, Sultanate of Oman.

Received for publication Nov 11, 2005; revisions received Dec 11, 2005; accepted for publication Dec 16, 2005.

Address for reprints: Vishwanath Golash, MS, FRCS, Department of Surgery, Sultan Qaboos Hospital, PO Box 98, Salalah, Pin Code 211, Sultanate of Oman (E-mail: golash@omantel.net.om and haritagolash@hotmail.com).

J Thorac Cardiovasc Surg 2006;131:1413-4

$0022-5223 / \$ 32.00$

Copyright $\odot 2006$ by The American Association for Thoracic Surgery doi:10.1016/j.jtcvs.2005.12.069

\section{Clinical Summary}

A 35-year-old full-term woman was referred from a remote area with a history of obstructed labor for the previous 3 days. On examination,



Dr Golash she was ill looking, pale, and toxic; had a blood pressure (BP) of 170/110 mm Hg; had a pulse of 104 beats/min; was febrile; and had gross peripheral edema. Per the abdomen, there were no palpable uterine contractions and no audible fetal heart sounds. On vaginal examination, the cervix was fully dilated. Urgent ultrasonography of the abdomen showed full-term uterus and no fetal movement. Gross crepitations were heard on both sides of the chest. Her initial diagnosis was pregnancy-induced hypertension, preeclampsia, intrauterine death of the child, and septicemia. Her investigations showed anemia, hypoalbuminemia, respiratory and metabolic acidosis, hypoxia, and septicemia. The chest radiograph and computed tomographic (CT) scan were suggestive of aspiration pneumonia. She was resuscitated. The dead fetus and placenta were delivered by means of emergency caesarian section. Postoperatively, she was ventilated because of poor oxygen saturation. Her subsequent repeated chest 


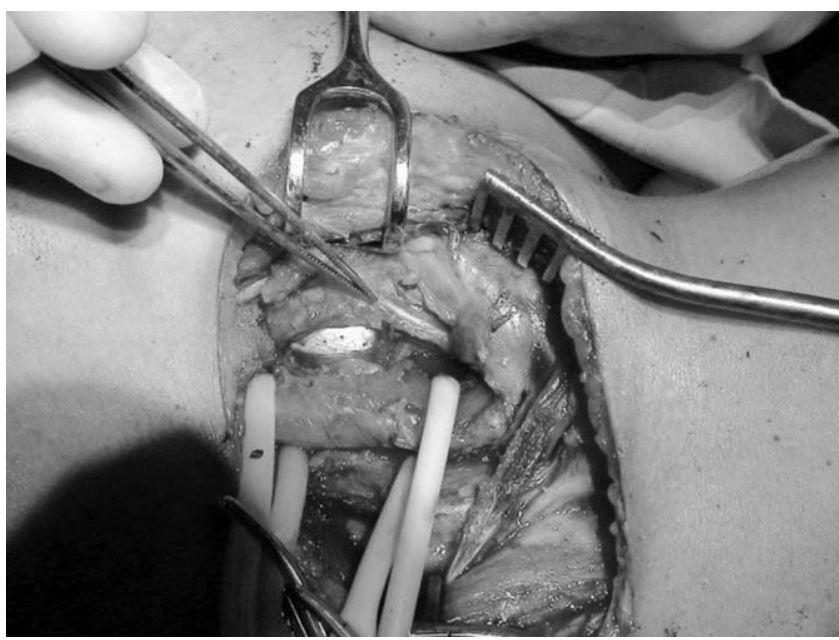

Figure 1. The esophagus is retracted on the slings, and the endotracheal tube is seen through the tracheoesophageal fistula. The forceps are pointing at the left recurrent laryngeal nerve.

radiographs and chest CT scans showed persistent, unresolving right-sided pneumonia. A tracheostomy was performed to assist with ventilation. She was fed through a nasogastric tube. Three weeks after her tracheostomy, the contents of the nasogastric tube feeding were seen coming through the tracheostomy tube. A TEF was suspected, which was subsequently confirmed by means of endoscopy, gastrograffin study, and a CT scan. TEF was localized $4 \mathrm{~cm}$ below the vocal cords, $15 \mathrm{~cm}$ from the incisors, and was 2.5 to $3 \mathrm{~cm}$ in length.

A laparoscopic drainage gastrostomy and feeding jejunostomy (tube within a tube) was performed successfully. ${ }^{1}$ The patient's chest and nutrition status improved over the coming weeks, and she was taken up for definite repair of TEF.

Through a long incision along the medial border of the left sternocleidomastoid muscle, the TEF was exposed. There was a fistulous defect of nearly 2 to $3 \mathrm{~cm}$ in length between the membranous part of the upper trachea and the esophagus (Figure 1). The healthy membranous part of the trachea was repaired with absorbable 3-0 Vicryl sutures (Ethicon, Inc, Somerville, NJ) on the endotracheal tube without any undue tension and without compromising the lumen size. The esophagus was closed over the nasogastric tube by using inner interrupted 3-0 Vicryl and outer 3-0 silk sutures (Figure 2). A sternothyroid muscle pedicle flap was sutured to prevertebral fascia covering the tracheal suture line, and because the defect was large, we interposed a second pedicled muscle flap of sternocleidomastoid muscle covering the esophageal suture line. ${ }^{2}$ The wound was closed on a suction drain. A new tracheostomy was created further down from the tracheal suture line.

Postoperatively, the jejunostomy feeding was reestablished, and the nasogastric tube was removed. The gastrograffin study done a week after the operation showed no sign of leak, and the patient gradually resumed normal feeding. The gastrostomy tube

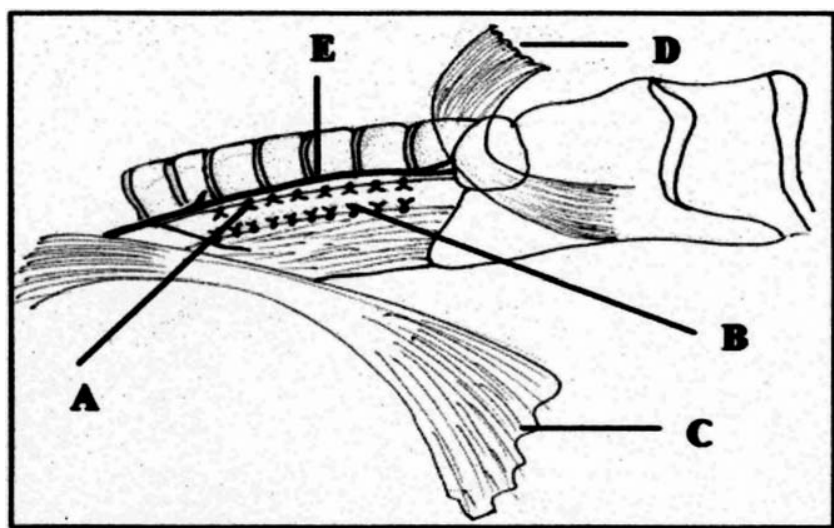

Figure 2. Repair of the esophagus and trachea: $A$, repair of the membranous part of the trachea; $B$, repair of the esophagus; $C$ and $D$, sternocleidomastoid and sternothyroid muscle pedicle flaps, respectively; $E$, recurrent laryngeal nerve.

with jejunostomy and tracheostomy tubes were removed subsequently. Six months after the primary repair, the patient was asymptomatic.

\section{Discussion}

Patients with TEF caused by endotracheal intubation are usually very critically ill. The first stage of treatment involves the diversion of salivary and gastric contents away from the fistula site, improving the nutritional status and control of sepsis. A drainage gastrostomy and feeding jejunostomy is performed either by means of percutaneous endoscopic gastrostomy and jejunostomy or by means of combined laparoendoscopy. Esophageal ligation and salivary fistula are seldom required.

Final repair of the fistula is delayed until the patient is weaned off the ventilator because positive pressure would cause anastomotic breakdown and recurrence of the fistula. There are several surgical techniques of repair of TEF. Repair can be done as a single-stage or a 2-stage procedure, with or without the interposition of pedicle muscle flap and tracheal resection. ${ }^{3,4}$ A large TEF with tracheal stenosis might require resection anastomosis of the trachea. A high-volume, low-pressure cuffed endotracheal tube would reduce the incidence of acquired TEF.

\section{References}

1. Reed MF, Mathisen DJ. Tracheoesophageal fistula. Chest Surg Clin N Am. 2003;13:271-89.

2. Baisi A, Bonavina L, Narne S, Peracchia A. Benign tracheoesophageal fistula: results of surgical therapy. Dis Esophagus. 1999;12:209-11.

3. Macchiarini P, Verhoye JP, Chapelier A, Fadel E, Dartevelle P. Evaluation and outcome of different surgical techniques for postintubation tracheoesophageal fistulas. J Thorac Cardiovasc Surg. 2000;119:26876.

4. Wolf M, Yellin A, Talmi YP, Segal E, Faibel M, Kronenberg J. Acquired tracheoesophageal fistula in critically ill patients. Ann Otol Rhinol Laryngol. 2006;109:731-5. 